\title{
CAMA
}

Centre for Applied Macroeconomic Analysis

\section{Financialization and Speculative Bubbles - International Evidence}

\section{CAMA Working Paper 6/2017 January 2017}

Ehsan Ahmed

James Madison University

J. Barkley Rosser, Jr.

James Madison University and

Centre for Applied Macroeconomic Analysis, ANU

Jamshed Y. Uppal

Catholic University of America

\begin{abstract}
Countries across the globe have undergone financialization of their economies over the recent decades. Concomitantly, asset markets have exhibited high levels of volatility with sharp increases characteristic of speculative bubbles followed by even sharper crashes. This paper attempts to test the possible presence of nonlinear speculative bubbles in 23 international markets using daily data from January 1993-March 2015, and its possible link to the financialization phenomenon. To estimate fundamental values, we estimate VAR models for each market for stock market returns with world interest rates, exchange rates, and world stock indexes as the fundamental variables. Residuals from these VAR national market models are tested for significant movements away from the fundamentals using Hamilton regime switching and Hurst rescaled range tests. After removing $A R C H$ effects from the residuals the remaining series is tested for nonlinearities using BDS statistics. Our results indicate the presence of speculative bubbles in all 23 of these markets with increasing incidence over time, which suggest a linkage with the phenomenon of financialization of the economies over the period.
\end{abstract}




\title{
Keywords
}

bubbles, emerging markets, nonlinear speculation

\author{
JEL Classification
}

Address for correspondence:

(E) cama.admin@anu.edu.au

ISSN 2206-0332

The Centre for Applied Macroeconomic Analysis in the Crawford School of Public Policy has been established to build strong links between professional macroeconomists. It provides a forum for quality macroeconomic research and discussion of policy issues between academia, government and the private sector.

The Crawford School of Public Policy is the Australian National University's public policy school, serving and influencing Australia, Asia and the Pacific through advanced policy research, graduate and executive education, and policy impact. 


\title{
FINANCIALIZATION AND SPECULATIVE BUBBLES - INTERNATIONAL EVIDENCE
}

\author{
Ehsan Ahmed; James Madison University \\ J. Barkley Rosser, Jr.; James Madison University and \\ Centre for Applied Macroeconomic Analysis at Australian National University \\ Jamshed Y. Uppal; Catholic University of America
}

December 17, 2016

\begin{abstract}
:
Countries across the globe have undergone financialization of their economies over the recent decades. Concomitantly, asset markets have exhibited high levels of volatility with sharp increases characteristic of speculative bubbles followed by even sharper crashes. This paper attempts to test the possible presence of nonlinear speculative bubbles in 23 international markets using daily data from January 1993-March 2015, and its possible link to the financialization phenomenon. To estimate fundamental values, we estimate VAR models for each market for stock market returns with world interest rates, exchange rates, and world stock indexes as the fundamental variables. Residuals from these VAR national market models are tested for significant movements away from the fundamentals using Hamilton regime switching and Hurst rescaled range tests. After removing ARCH effects from the residuals the remaining series is tested for nonlinearities using BDS statistics. Our results indicate the presence of speculative bubbles in all 23 of these markets with increasing incidence over time, which suggest a linkage with the phenomenon of financialization of the economies over the period.
\end{abstract}

Keywords: bubbles, emerging markets, nonlinear speculation 


\section{FINANCIALIZATION AND SPECULATIVE BUBBLES - INTERNATIONAL EVIDENCE}

\section{Introduction:}

In the recent years the phenomenon of financialization has come in the limelight. It refers to the growing dominance of financial instruments and markets over the traditional industrial and agricultural economies, and is connected with the concomitant development of cyberspace, the global deregulation of financial markets, and the rise of shareholder governance (Lagoarde-Segot, 2016). ${ }^{1}$ In its broader impact financial markets, financial institutions and financial elites gain greater influence over economic policy and economic outcomes (Palley, 2007).

Since the Global Financial Crisis (GFC) of 2007-09 the financialization literature has focused on its negative consequences for the economies. Palley (2007) lists the principal impacts of financialization as: (i) elevating the significance of the financial sector relative to the real sector; (ii) transferring income from the real sector to the financial sector; and (iii) increasing income inequality and contributing to wage stagnation. Additionally, financialization may render the economy prone to risk of debt-deflation and prolonged recession. Aalbers et al. (2015) present a case study of the financialization of both housing and the state in the Netherlands documenting its negative consequences.

Financialization is seen as breaking the traditional link between the real economy and the financial sector, which was to facilitate flow of capital to the real sector; thus, the returns on the real assets would be reflected in the financial market. However, financialization has led to a decoupling of the two sectors which has frequently manifested it-self in periods of speculative bubbles and booming financial markets in the face of stagnant economies. The economic bubbles may last for some time but ultimately burst and in many cases lead to financial crisis and economic depression. The Global Financial Crisis of 2007-09 is a stark example of such a case. The GFC which originated in the US mortgage market was fueled by engineered complex financial products such as the Mortgage Backed Securities (MBS) and Credit Default Swaps (CDS) which allowed securitization of real assets. When the housing price bubble burst in the US it unleashed "weapons of mass-destruction" across the globe and pushed many countries in to the

\footnotetext{
${ }^{1}$ According to Aalbers (2015) the financialization literature seeks to conjoin real-world processes and practices that are otherwise treated as discrete entities; it addresses how the financialization of the global economy is tied to the financialization of the state, economic sectors, individual firms, and daily life. Gupta (2015) provides a brief review of the literature on "financialization" and the causes for the emergence of this phenomenon. For a more detailed treatment, see Epstein (2005).
} 
Great Recession. The impact of the crisis was magnified because of the financialization and globalization of the financial markets (Aalbers, 2008).

Cloke $(2010,2013)$ suggests that the global financial crisis "represents a distinctly new form of actor-network capitalism, originating in the hybrid financial innovations since the 1970s, the explosive growth in cyber-space potential during the 1990s and the subsuming of the State by finance that accompanied these two processes." The author suggests that the evolution of ultracapital (capital beyond capital) from within the global financial services sector, has contributed to the recurrent financial crisis. Vitali et al. (2011) suggest that the structure of the control network of transnational corporations creates a small tightly-knit core of financial institutions, an economic "super-entity" which affects global market competition and financial stability. An analysis of financial crises since 1945 by Kaminsky \& Reinhart (1999) demonstrates that financial liberalization has proceeded in the majority of cases. Aalbers (2008) suggests that liberalization-enabled securitization and financialization, by embracing risk rather than avoiding it, act against the interests of long-term investments. "Through financialization, the volatility of Wall Street has entered not only companies off Wall Street, but increasingly also individual homes."

The link between financialization and increasing incidence of speculative bubble and financial crisis is of particular importance to the developing countries. For the past quarter of a century these countries have consciously followed public policies to foster financial sector development. Enabling legal and regulatory structures have been put in place to accommodate financial innovations and products such as financial derivatives. The complexity of the engineered products at times seems to be beyond the governance and regulatory capacity of many of the developing countries. However, the acceptance and rationalization of the reliance on financial markets and products is anchored in the neo-liberal and free-market doctrines and in the structural discourse Walter (2016) terms as the "financial logos." Liberalization and globalization have been embraced all over the world with many developing countries moving towards these regimes with speed. The Global Financial Crisis has, however, inserted a cautionary note in this narrative, in particular, the question is being raised as to what extent financialization of an economy leads to increasing incidence of speculative bubbles and resulting economic crisis. The question is of significance to the development of public policies aimed at containment of the associated ill-consequences of the increasing role of the financial sector in the economy. 
The objective of this study is to examine the incidence of speculative bubbles in the selected sample countries since market liberalization measures were taken in the 1990s. The next section describes the evolution of financial sectors and the structural changes in the emerging markets which have contributed to greater dominance of the financial sector in the economies. The third section lays out the theory of financial bubbles. The next section explains our methodology and data used in the study, which is followed by a section on the empirical results. The final section summarizes our findings and presents the conclusions.

\section{An Overview of Financialization}

Countries across the globe have seen fundamental structural changes in their economies and financial markets over our study period, roughly 1993-2015, leading to financialization of their economies to varying extent. Our sample consists of 23 non-Western economies, with developing countries in the majority. Tables $1 \mathrm{a}$ and $1 \mathrm{~b}$ portray salient features of these economies for the selected years 1993, 2001, 2008 and 2013, to capture the development of the economies and the key indicators of financialization over the study period.

As Table 1a shows, the sample includes large economies in terms of GDP (e.g., India, Mexico and Brazil) as well as smaller economies (e.g., Sri Lanka, and Morocco), and countries at various stages of development, in terms of Gross National Income per capita (e.g., Bangladesh and Singapore). Majority of the sample falls in the emerging or frontier markets category, though Hong Kong, Singapore and South Korea are classified as developed markets. The countries vary widely across regions and economic systems. There is also a considerable disparity in their growth rate over the period, and economic structure. Since the beginning of the study period (1993) statistics, one can see that overall the economies have experienced substantial economic growth. The countries recorded an average rate of GDP growth of 4.5\% during the 1993-2001 period which accelerated to $13.7 \%$ p.a. during the following seven years (2001-08), but dropped to $6.2 \%$ p.a. following the global financial crisis starting 2008 .

An important development has been the increasing role of the financial markets in the countries' economies. The total equity market capitalization for the countries in the sample increased from US\$ 840 billion to US\$ 1,644 billion in 2001, registering an annual growth rate of $4.4 \%$. The total capitalization, however, increased three times in the following seven years to US\$ 4,966 billion, at an annual rate of $15.6 \%$. Following the Global Financial Crisis, however, the total market capitalization further increased by about $2 \frac{1}{2}$ times to US $\$ 11,946$ billion in the next five years (at annual compound growth rate of 19.2\%). 
The average market capitalization as a percentage of the GDP, which had remained in the range of $86 \%-78 \%$ up to 2008, increased to $133 \%$ by the end of 2013 as can be seen in Table $1 \mathrm{~b}$. The table also provides salient statistics for the stock markets in the sample countries for the selected years for comparison. The table shows stocks traded (total value in current US\$), number of listed domestic companies, total market capitalization of listed domestic companies (\% of GDP), the total value stocks traded (\% of GDP), and the turnover ratio of domestic shares traded. All statistics show robust markets growth and a high level of trading activity indicating financialization of the economies. However, there has been substantial disparity within the sample as to both the market growth as well as market activity.

Over the study period the emerging markets have implemented important capital market reforms, which have included stock market liberalization, improvements in securities clearance and settlements mechanisms, and the development of regulatory and supervisory frameworks. The privatization of state-owned enterprises and the development of financial institutions such as privately managed pension funds, have further spurred the growth in the capital markets. These capital markets reforms taken in the early 1990's were part of the overall financial liberalization efforts, and included liberalizing interest rates, shifting to indirect instruments of monetary control, dismantling directed credit, and opening the capital account to foreign flows. In the mid 1990's the emphasis of reforms was on strengthening financial sector infrastructure and individual institutions. During this period, the scope of the financial sector reforms expanded to include strengthening the legal framework for the banking systems, and developing regulatory framework and governance environment for corporate sector and securities markets. At the same time strengthening the enforcement of insider trading laws, accounting and auditing standards were emphasized.

In the wake of the Asian financial crisis (1997-98) the financial sector reforms assumed a new urgency. The crisis demonstrated that the corporate and financial sectors are interlinked and the adverse events in one can have consequences for the other. The reforms that followed these crises focused on the need for greater transparency and accountability, and ownership structure. The developing countries implemented a number of fundamental reforms for improving transparency and accountability. These included steps for improving disclosure of macroeconomic information, disclosure requirements for securities markets participants, and investor education. The countries saw establishment of rating agencies and credit bureaus and adoption of international accounting and auditing standards. 
In the 2000's the deepening and broadening of the financial markets continued. The countries have seen expansion and maturation of financial institutions such as mutual funds, pension funds, and insurance companies, many of which were established in the mid-1990s. The availability of financial instruments has been broadened with the establishment and expansion of derivative markets, commodities exchanges, and electronic trading platforms. In a number of these markets a variety of derivative instruments have been made available for hedging risk, although as the financial crisis of late 2008 warns us, sometimes the availability of some of these instruments may reduce the broader resilience of the financial system, even as they increase the ability of agents to manage risk in the short run.

The Global Financial Crisis of 2008 (GFC) has had far reaching and extreme effects on the financial markets crosswise over nations. Stock market volatility expanded numerous folds throughout the time of crisis, all economic sectors encountering extreme returns. Exceptional expansive swings in the stock prices were seen with a recurrence which had never been experienced previously. This brings up a fascinating issue of whether the financial markets over the globe experienced speculative bubbles leading to the financial crisis, and has the experience of financial crisis led to a toning downing of the animal spirits associated with such bubbles. The Global Financial crisis period provides us with an opportunity to investigate the incidence of speculative behavior of the stock markets over time as financialization took hold. In the past, financial and monetary crisis, such as the Asian Flu, the Tequila Crisis or the Russian Virus, have tended to be preceded by periods of speculations. These crashes have been infectious across countries and have prompted gigantic bailouts by the global organizations to stem contagion.

\section{Theoretical Problems of Speculative Bubbles}

The conventional theoretical approach to speculative bubbles in the financial economics literature has been to identify it as a price of an asset staying away from the fundamental value of the asset for some extended period of time. While it is easier to theoretically hypothesize the existence of stationary bubbles that can easily arise in overlapping generations models, even with homogeneous agents possessing rational expectations (Tirole, 1985), such as has been argued is the case for fiat monies with positive values (whose fundamental values are presumably zero, or barely above it, "the value of the paper the money is printed on"), such bubbles are essentially impossible to identify in practice. It is the exploding bubbles, or at least the sharply increasing ones, that we have any hope of empirically observing, even if the theory behind how they can arise is less general than that for the stationary bubbles. 
In any case, this standard approach would be to identify a bubble by

$$
b(\mathrm{t})=p(\mathrm{t})-f(\mathrm{t})+\varepsilon(\mathrm{t})>0,
$$

where $t$ is the time period, $b$ is the bubble value, ${ }^{2} p$ is the price of the asset, $f$ is the fundamental value of the asset, and $\varepsilon$ is an exogenous stochastic noise process, usually posited to be i.i.d., although we recognize that in practice asset returns in many financial markets exhibit kurtosis and other non-Gaussian properties. In theory for simple financial assets, this is argued to be the present discounted sum of future, rationally expected net returns on the asset.

One famous model that allows for rational bubbles is due to Blanchard and Watson (1982), that of the stochastically crashing rational bubble. Another is the stationary bubble model in overlapping generations of Tirole (1985).

At the opposite extreme from the various models of rational bubbles is the view that bubbles are inherently totally irrational, with agents, including even professional traders, falling into overly optimistic moods during speculative booms, to be followed by emotions of more negative and panicky sorts after a bubble peaks. Shiller (2015) is a strong advocate of this view and presents the data and arguments to support it in detail, with this view tracing back to the late Charles Kindleberger (2000), his mentor, Hyman Minsky (1972), and even to some classical political economists from the 1700 and 1800s.

A more widely used approach has been to look to the middle between these views of agents, to accept that they are heterogeneous in many ways, including that some may have rational expectations while others do not. There had been an older literature that accepted this (Baumol, 1957), sometimes emphasizing a conflict between "fundamentalists" who stabilize the market by buying when the asset price is below the fundamental and selling when the asset price is above the fundamental and the "chartists" who tend to chase trends in the price dynamic and thus destabilize the market, creating excess volatility, if not necessarily outright bubbles (Zeeman, 1974). This view fell out of favor as the 1970s proceeded, and the rational expectations revolution took place.

The idea of using heterogeneous agents was revived by Black (1986), who posited the existence of "noise" traders who follow no particular strategy or rule, or arbitrary ones, and who interact with a group having rational expectations. Depending on the strategies they use, the noise traders can at times destabilize markets and create bubbles, much like the chartists of older

\footnotetext{
${ }^{2}$ While we define bubbles here as being positive, our econometric tests will catch negative bubbles as well, really testing for significant changes in a possible value $b$ in one direction or another.
} 
models. Day and Huang (1990) followed this with a model that added market makers to this setup and showed the possibility of a wide variety of dynamic paths for asset prices, including dynamically chaotic ones. Impetus for such an approach increased after DeLong et al (1991) demonstrated that such noise traders could not only survive but even thrive in markets that also contained traders with rational expectations, thus overturning an old argument that such traders would lose money and be driven from the markets.

Eventually this general approach evolved to allow for wider varieties of heterogeneous interacting agents, who could learn and change strategies over time, with Föllmer et al (2005) providing a general theoretical perspective on such approaches and Hommes (2006) and LeBaron (2006) provide broad summaries and reviews of them. We shall look briefly at one such model that can produce a wide variety of dynamic paths, due to Bischi et al (2006), which in turn draws on Chiarella et al (2003), a discrete choice model of agents whose strategies evolve over time in response to their performance. This approach was initiated by Brock and Hommes (1997).

In Bischi et al (2006) we find the following setup, which is in discrete time steps, t. The basic unknown price dynamics are given in Equation (2), where $w$ is a measure of excess demand and $g(w(t))$ then measuring "the influence of excess demand on current price variations," with $\mathrm{g}(0)=0$ and $\mathrm{g}^{\prime}(w(\mathrm{t}))>0$. The final term is composed of a Gaussian noise term, $\varepsilon$, with $\sigma$ being its standard deviation,

$$
p(\mathrm{t}+1)-p(\mathrm{t})=\mathrm{g}(w(\mathrm{t}))+\sigma_{\varepsilon} .
$$

Individual agents, $\mathrm{i}$, act on utility functions that include a term, $J$, that represents their sensitivity to what other agents are doing, in effect the determinant of herding behavior, or "proportional spillovers," as well as expectational terms about price and excess demand, which are indicated by a superposed *. This is shown in Equation (3),

$$
U_{i}\left(w_{i}(\mathrm{t})\right)=\left(p^{*}(\mathrm{t})-p(\mathrm{t}) w_{i}(\mathrm{t})\right)+J w_{i}(\mathrm{t}) w(\mathrm{t})^{*}+\varepsilon_{i}\left(\mathrm{t}, w_{i}(\mathrm{t})\right)
$$

Price expectations formation is given by by Equation (4),

$$
p^{*}(\mathrm{t}+1)=p^{*}(\mathrm{t})-\rho\left(p^{*}(\mathrm{t})\right),
$$

with $\rho$ representing a "speed of adjustment" parameter such that $\rho \varepsilon[0,1]$. In turn, expectations regarding excess demand are given in Equation (5), which includes a parameter, $\beta$, which indicates the degree of willingness of agents to change their strategies,

$$
w(\mathrm{t}+1)=\tanh \left[\beta\left(p^{*}(\mathrm{t})-p(\mathrm{t})+w(\mathrm{t}) J\right)\right] .
$$


It turns out that the nature of the dynamics are ultimately shaped by the respective values of $\beta$ and $J$, with generally speaking more volatile and complex dynamics arising when these parameters are of higher values above certain critical levels. ${ }^{3}$ Simulations of this model are able to replicate patterns that we see regularly in financial markets, with periods of relatively stable behavior alternating with periods of heightened volatility, driven by oscillations in which different strategies are dominant among the agents at different times.

We close this section by noting that this is simply a representative model, which we are not attempting to estimate per se in what follows (the relevant parameters being hard to estimate from actual market data), which uses a more generic time-series approach, although we do model the fundamental with a vector auto-regression (Engle, 1982) that uses certain macroeconomic variables.

\section{Data and Methodology:}

This paper uses methods from Ahmed et al (2006, 2010), which in turn combined methods used in Ahmed et al (1996) and in Ahmed et al (1997) ${ }^{4}$, to test for the absence of excessively rapid movements of price movements in daily stock market indices in 23 market economies from 1993 to 2015 as well as to test for absence of nonlinearities beyond ARCH effects. Failure to reject such absences is seen as possible evidence for the presence of nonlinear speculative bubbles in such markets. This would confirm a widely held perception that many such markets have exhibited such bubbles, possibly even more so than the markets of either more fully developed or less developed economies (although we do not test for either of these last hypotheses). While such bubbles are seen as destabilizing and disruptive to these economies in many ways, they are also seen as often accompanying waves of real investment that are crucial to the development process, which means that a nation may or may not wish to reduce or eliminate such bubbles.

Our method is to estimate time-series for likely fundamentals of the daily stock market indices using vector auto-regressions (VAR) of the stock market index returns with a leading country interest rate, the country's foreign exchange rate, a world interest rate, and average world

\footnotetext{
${ }^{3}$ This approach draws ultimately from statistical physics of interacting particle systems, with $\beta$ being related to temperature and $J$ related to the strength of interactions between the particles. These parameters are difficult to estimate from actual data. An extension of this approach that brings in the Minsky approach is due to Gallegati et al (2011), with a further discussion of related policy issues by Rosser et al (2012). ${ }^{4}$ Ahmed et al (1996) studied such phenomena in the Pakistani stock market while Ahmed et al (1997) looked at such bubbles in closed-end country funds. In addition, Ahmed et al (2006) focused on the Chinese stock markets of the 1990s, with Ahmed et al (2010) applying this to a set of emerging market stock markets prior to the Great Recession.
} 
stock market returns. We then subject the residuals of these hypothesized fundamental series for each country to two separate tests for excessively rapid movements away from the fundamental (or more precisely test for the absence of such movements). The first test is the regime switching test due to Hamilton (1989) and the second is the rescaled range analysis (RRA) due originally to Hurst (1951). We then estimate and remove ARCH effects for each series and test for the absence of additional nonlinearities using the BDS test (Brock et al, 1997), although we do not seek to determine more precisely the forms of these nonlinearities, which presumably vary from country to country. For all countries, at the $1 \%$ level of significance we fail to reject the absence of such bubbles, the presence of further nonlinearities beyond ARCH, using the BDS test.

A number of efforts have been made recently by others to study such dynamics in one form or another in such markets, with much of the focus being on the especially volatile stock markets of China. Ahmed et al (2006) studied this issue for 1999 data, and were unable to reject the presence of nonlinear bubbles. Jiang et al (2010) found long memory in the Chinese and Japanese stock markets using detrended fluctuation analysis, indicative of rejection of the efficient market hypothesis. Thiele (2014) finds persistence and fractal patterns in the Chinese market and suggests that regulations may have aggravated the potential for bubbles ${ }^{5}$. Sarkar and Mukhopadhyay (2005) found a variety of anomalies and nonlinear dependence in the Indian stock markets, with Hiremath (2014, chaps. 5-6) providing more detailed discussion of the Indian case. Ciner and Karagozoglu (2008) have found such nonlinear bubbles to arise from asymmetric information in the Turkish stock market.

At this point we warn of an important caveat to this analysis. This is the ubiquitous problem of the misspecified fundamental, first identified by Flood and Garber (1980). The problem is that to identify a bubble one must be certain that one has correctly identified the fundamental series from which it is seen to be deviating from. What one sees as a bubble might actually be the fundamental if it reflects rational expectations of a substantial increase in the future of the fundamental that simply turns out not to be realized. Only a few assets can avoid this problem to some extent, with closed-end funds whose fundamentals are the values of the assets constituting them (with some adjustment for tax or liquidity matters) being such an example (Ahmed et al, 1997). Thus, while our approach to estimate the fundamental series for these stock markets has been used by others (Canova and Ito, 1991), we cannot guarantee that we have determined proper fundamentals for these stock markets. So, even though the evidence we

\footnotetext{
${ }^{5}$ These dynamics have also happened despite China maintaining capital controls in its foreign exchange markets, something recommended even by Bhagwati (2007) who supports free trade and increased economic globalization in general.
} 
present is quite strong for almost all of these markets, it cannot be viewed as conclusive. However, even if we cannot say for certain that we have identified speculative bubbles, the econometric techniques we use can be said to identify sharp movements that can be identified as at least constituting "high volatility."

\section{Empirical Tests of Speculative Bubbles}

We examine daily returns behavior in the sample countries over periods 1993-2013. For each country, we use daily values of the market's major index, and compute stock index 'returns' as the first log differences; $\mathrm{R}_{\mathrm{I}, \mathrm{t}}=\ln \left(\operatorname{Index}_{\mathrm{t}}\right)-\ln \left(\operatorname{Index}_{\mathrm{t}-1}\right)$. These index returns were then used in a Vector Autoregressive (VAR) model with those of daily interest rates, daily exchange rates and World Stock index returns as a measure of the presumptive fundamental. Two alternative series of interest rates were used for some countries; the first representing short-term rates for 30-days or less maturity and the second set of interest rate series represented rates on relatively longerterm one year maturity instruments. ${ }^{6}$ These interest rates were proxied, depending on the availability of data for each country, by various rates series, including CD rate, inter-bank overnight rate, T-Bill auction yields, bank base rates, and bank loan rates. To capture the impact and the linkages of the developed markets on the fundamental of the sample countries we also included MSCI World index in the VAR model. The MSCI World index, maintained by Morgan Stanley Capital International, is considered a stock market index of 'world portfolio' and includes a collection of stocks of all the 23 developed markets in the world, as defined by MSCI, for which returns are calculated as for the local indices. The data on the stock market indices, interest rates and exchange rates was obtained from the Datastream International, Ltd. database.

Residuals from the resulting VARs are used for the bubble tests, with ARCH effects removed later for the BDS nonlinearity tests. We then carry out three types of tests: (i) the regime switching tests, (ii) the rescaled range tests, and the (iii) nonlinearity tests.

\section{i) Regime Switching Tests}

Hamilton (1989) introduced an approach to regime switching tests that can be used to test for trends in time series and switches, with a more complete analysis in Hamilton, (1994, Chap. 22). We use this approach as our main test for the null of no bubbles on the residual series derived above which is given by

$$
\epsilon_{\mathrm{t}}=\mathrm{n}_{\mathrm{t}}+\mathrm{z}_{\mathrm{t}}
$$

\footnotetext{
${ }^{6}$ Arguably we should include a measure of monetary policy. However, such policies do not change daily except as manifested in daily changes of interest rates.
} 
where

$$
\mathrm{n}_{\mathrm{t}}=\mu_{1}+\mu_{2} \mathrm{~s}_{\mathrm{t}}
$$

and

$$
\mathrm{z}_{\mathrm{t}}-\mathrm{z}_{\mathrm{t}-1}=\mathrm{N}_{1}\left(\mathrm{z}_{\mathrm{t}-1}-\mathrm{z}_{\mathrm{t}-2}\right)+\ldots+\mathrm{N}_{\mathrm{r}}\left(\mathrm{z}_{\mathrm{t}-\mathrm{r}}-\mathrm{z}_{\mathrm{t}-\mathrm{r}-1}\right)+\gamma_{\mathrm{t}}
$$

with $\mathrm{s}=1$ being a positive trend, $\mathrm{s}=0$ being a negative trend, and $\mathrm{:}_{\mathrm{I}} \neq 0$ indicating the possible existence of a trend element beyond the VAR process. Furthermore, let

$$
\begin{aligned}
& \operatorname{Prob}\left[\mathrm{s}_{\mathrm{t}}=1 \mathrm{~s}_{\mathrm{t}-1}=1\right]=\mathrm{p}, \operatorname{Prob}\left[\mathrm{s}_{\mathrm{t}}=0 \mathrm{~s}_{\mathrm{t}-1}=1\right]=1-\mathrm{p} \\
& \operatorname{Prob}\left[\mathrm{s}_{\mathrm{t}}=0 \mathrm{~s}_{\mathrm{t}-1}=0\right]=\mathrm{q}, \operatorname{Prob}\left[\mathrm{s}_{\mathrm{t}}=1 \mathrm{~s}_{\mathrm{t}-1}=0\right]=1-\mathrm{q} .
\end{aligned}
$$

Following Engel and Hamilton (1990) a "no bubbles" test proposes a null hypothesis of no trends given by $\mathrm{p}=1 \mathrm{-}$. This is tested by with a Wald test statistic given by

$$
[p-(1-q)] /[\operatorname{var}(p)+\operatorname{var}(1-q)+\operatorname{covar}(p, 1-q)] .
$$

Results: The regime switching tests results are reported in table 2a which shows the $\chi^{2}$ values for the Wald Test for bubbles $\left(\mathrm{H}_{0}: p=1-q\right)$ as explained above. The critical value for rejecting the null of no trends is $\chi^{2}=3.8$. Clearly, the null is strongly rejected in all countries for the full sample period from $1 / 1 / 1993$ to $3 / 5 / 15$. In order to examine the incidence of speculative bubbles over time we sub-divide the full sample into four sub-periods as follows:

1.Sub-sample 1: Jan 1993 - Dec 1996 - 4 years, market liberalization, pre-dotcom bubble.

2. Sub-sample 2: Jan 1997 - Dec 2001 - 5 years, dotcom bubble and bust.

3. Sub-sample 3: Jan 2002 - Dec 2007 - 6 years, real estate bubble and bust.

4. Sub-sample 4: Jan 2008 - Mar 2015 - 6+ years, great recession and recovery.

The division also roughly corresponded to the statistics on the economies and the markets provided in tables 1 and 2.

Table $2 \mathrm{~b}$ contains the results of the regime switching tests for the four subsamples. The null hypothesis of no trends is strongly rejected in the preponderance of the tests (countries and the sub-samples), the test statistics exceeding the critical value of $\chi^{2}=3.8$. However, the null is not rejected for the sub-sample 4 for Brazil, Chile, Czech Republic and Hong Kong, and for subperiod 1 for Hungary and Indonesia. Also, for some sub-periods the statistic could not be computed due to insufficient data. Although, we did not conduct a formal statistical test for the difference in the incidence of bubbles across the four subsamples, the magnitude of the test statistic $\chi^{2}$ may be used to make an inference as to whether a market was more or less bubbly 
from one period to another. When we compare the values of the Wald test statistics from one period to the next we find that there is quite a variation in the $\chi^{2}$ value from one period to the other; countries depict a varied pattern across time. In the case of a few countries (India and South Africa) the Wald statistic shows an increase between each sub-period, i.e., sub-periods 2 vs 1,3 vs 2 and 4 vs 3 . We find that comparing sub-period 2 to sub-period 1 (the market liberalization period), the value of the test statistic increased in about half the sample (10 out of $21)$, but decreased in the other half (11/21). However, the markets depict a marked increase in the speculative behavior (as indicated by the magnitude of the $\chi^{2}$ statistic) when we compare subperiod 3 to 2 (the statistic is higher in 16 out of 20 countries), and sub-period 3 to 1 (the statistic is higher in 17 out of 21 countries). Comparing the sub-period 4 (the post Global Crisis period) to sub-period 3 (the pre-Global Crisis period) we find that the magnitude of the statistic decreased in majority of the markets (11 out of 19 countries), in particular we see no evidence of the presence of speculative tends in four countries, as noted above. Nevertheless, the value of the statistic is higher for half the sample. The post-Global Crisis period seems to have attenuated the incidence of speculative bubbles to some extent. Yet, the overall picture is that there seems to be a secular trend towards increasing tendency for the market to exhibit speculative behavior.

\section{ii) Hurst Persistence Tests}

Hurst (1951) developed a test to study persistence of Nile River annual flows, which was first applied to economic data by Mandelbrot (1972). For a series $x_{t}$ with $n$ observations, mean of $x^{*} m$ and a max and a min value, the range $\mathrm{R}(\mathrm{n})$ is:

$$
\mathrm{R}(\mathrm{n})=\left[\max 1 \leq \mathrm{k} \leq \mathrm{n} \sum_{j=1}^{k}\left(\mathrm{x}_{j}-\mathrm{x}^{*}\right)-\min 1 \leq \mathrm{k} \leq \mathrm{n} \sum_{j=1}^{k}\left(\mathrm{x}_{j}-\mathrm{x}^{*}\right)\right]
$$

The scale factor, $\mathrm{S}(\mathrm{n}, \mathrm{q})$ is the square root of a consistent estimator for spectral density at frequency zero, with $\mathrm{q}<\mathrm{n}$,

$$
\mathrm{S}(\mathrm{n}, \mathrm{q})^{2}=\mathrm{g}_{0}+2 \sum_{j=1}^{q} w_{j}(\mathrm{q}) \mathrm{g}_{\mathrm{j}}, \mathrm{w}_{\mathrm{j}}(\mathrm{q})=1-[\mathrm{j} /(\mathrm{q}-1)],
$$

with g's autocovariances and w's weights based on the truncation parameter, q, which is a period of short-term dependence. ${ }^{7}$ The classical Hurst case has $\mathrm{q}=0$, which reduces the scaling factor to a simple standard deviation.

Feller (1951) showed that if $\mathrm{x}_{\mathrm{t}}$ is a Gaussian i.i.d. series then

\footnotetext{
${ }^{7}$ Lo (1991) has criticized the use of the classical Hurst coefficient for studying long-term persistence in stock markets precisely because of this presence of short-term dependence for which he proposes a method to avoid such dependence. However, this is not a problem for us because it is precisely short-term dependence that we are interested in detecting.
} 


$$
\mathrm{R}(\mathrm{n}) / \mathrm{S}(\mathrm{n}) \propto \mathrm{n}^{\mathrm{H}},
$$

$\mathrm{H}=1 / 2$ implies integer integro-differentiation and thus standard Brownian motion, the "random walk." $H$ is the Hurst coefficient, which can vary from zero to one with a value of $1 / 2$ implying no persistence in a process, a value significantly less than $1 / 2$ implying "anti-persistence" and a value significantly greater than $1 / 2$ implying positive persistence. The significance test involves breaking the sample into sub-samples (namely, pre-bubble, during-bubble and post-bubble period) and then estimating a Chow test on the null that the sub-periods possess identical slopes. This technique is also called rescaled range analysis. Sub-samples are determined on visual examination of the entire stock returns series. While we did not use a formal technique to seek structural breaks, we note that the bias for not doing so is to weaken the results as such techniques work to maximize the differences between the various sub-samples.

Results: The Hurst persistent test is conducted for two sample, pre- and Global Financial Crisis (2007) periods; first period is from January 2002 to December 2007, and the second is from January 2008 to March 2015. Table 3 presents the results of this test.

For each country $\mathrm{H}$ (Hurst) coefficient is estimated and as can be seen the value of the estimated value of the coefficient is above 0.50 for all countries in both sub-periods, except for one Brazil, $(\mathrm{H}=0.46)$ for the pre-GFC period and for Poland $(\mathrm{H}=0.50)$ and South Africa $(\mathrm{H}=0.46)$ for the post-GFC period. The median Hurst Coefficient is 0.58 for the first and 0.54 for the second period. The F values reported in the table are for the Chow tests which involves breaking the sample into sub-samples (namely, pre-bubble, during-bubble and post-bubble period) and then testing the null that the sub-periods data possess identical slopes, explained above.

As the table shows the computed F-values for all of the countries are substantially above the critical value showing a significant rejection of the null hypothesis that the coefficient is equal to 0.50 (thus indicating no persistence). Results are reported for a test of a model with the intercept suppressed.

\section{iii) Nonlinearity Tests}

We test for nonlinearity of the VAR residual series in two stages. The first is to remove ARCH effects. Engle (1982) showed that the nonlinear variance dependence measure of autoregressive conditional heteroskedasticity $(\mathrm{ARCH})$ as

$$
\mathrm{x}_{\mathrm{t}}=\delta_{\mathrm{t}} \mu_{\mathrm{t}}
$$




$$
\delta_{\mathrm{t}}^{2}=\alpha_{0}+\sum_{i=0}^{n} \alpha_{i} \mathrm{x}_{\mathrm{I}-\mathrm{i}}^{2}
$$

with $\mu$ i.i.d. and the $\alpha_{I}$ 's different lags. We use a three period lag and, as expected, found significant ARCH effects in all series, available on request from the authors. ${ }^{8}$

The second stage involves removing variability attributable to the estimated ARCH effects from the VAR residual series for both models. The remaining residual series is run through the BDS test due to Brock, Dechert, LeBaron, and Scheinkman (1997). This statistic tests for generalized nonlinear structure but does not test for any specific form such as alternative ARCH forms or chaos.

The correlation integral for a data series $\mathrm{x}_{\mathrm{t}}, \mathrm{t}=1, \ldots, \mathrm{T}$, results from forming $\mathrm{m}$-histories such that $\mathrm{x}=\left[\mathrm{x}_{\mathrm{t}}, \mathrm{x}_{\mathrm{t}+1}, \ldots, \mathrm{x}_{\mathrm{t}+\mathrm{m}+1}\right]$ for any embedding dimension $\mathrm{m}$. It is

$$
\mathrm{c}_{\mathrm{m}} \mathrm{T}(\varepsilon)=\sum_{t<s} \mathrm{I}_{\varepsilon}\left(\mathrm{x}_{\mathrm{t}}^{\mathrm{m}}, \mathrm{x}_{\mathrm{s}}^{\mathrm{m}}\right)\left[2 / \mathrm{T}_{\mathrm{m}}\left(\mathrm{T}_{\mathrm{m}}-1\right)\right]
$$

with a tolerance distance of $\varepsilon$, conventionally measured by the standard deviation divided by the spread of the data, $\mathrm{I}_{\varepsilon}\left(\mathrm{x}_{\mathrm{t}}^{\mathrm{m}}, \mathrm{x}_{\mathrm{s}}{ }^{\mathrm{m}}\right)$ is an indicator function equaling 1 if $\left|\mathrm{I}_{\varepsilon}\left(\mathrm{x}_{\mathrm{t}}{ }^{\mathrm{m}}, \mathrm{x}_{\mathrm{s}}{ }^{\mathrm{m}}\right)\right|<\varepsilon$ and equaling zero otherwise, and $\mathrm{T}_{\mathrm{m}}=\mathrm{T}-(\mathrm{m}-1)$.

The BDS statistic comes from the correlation integral as

$$
\operatorname{BDS}(\mathrm{m}, \varepsilon)=\mathrm{T}^{1 / 2}\left\{\mathrm{c}_{\mathrm{m}}(\varepsilon)-\left[\mathrm{c}_{1}(\varepsilon)\right]^{\mathrm{m}}\right\} / \mathrm{b}_{\mathrm{m}}
$$

where $b_{m}$ is the standard deviation of the BDS statistic dependent on the embedding dimension $\mathrm{m}$. The null hypothesis is that the series is i.i.d., meaning that for a given $\varepsilon$ and an $\mathrm{m}>1, \mathrm{c}_{\mathrm{m}}(\varepsilon)$ $\left[c_{1}(\varepsilon)\right]^{\mathrm{m}}$ equals zero. Thus, sufficiently large values of the BDS statistic indicate nonlinear structure in the remaining series. This test is subject to severe small sample bias with a cutoff of 500 observations sufficient to overcome this, a minimum both of our daily series easily achieve.

Results: Table 4 presents the results of this test for embedding dimensions, $\mathrm{m}=2$ to 4 ( $\mathrm{m}$ $=3$ is conventional). The critical value for rejecting the null of i.i.d. is approximately 6 . Based on the estimated BDS statistics null is rejected for all cases except one case (Israel sample 2). Thus, there appears to be remaining nonlinearity beyond basic ARCH in the VAR residual series.

Of course, just as our earlier tests are subject to the validity of our original VAR specifications, likewise so is this test. We emphasize that the nature of the remaining nonlinearity remains unknown. It is likely that different models of nonlinearity will work better for each

\footnotetext{
${ }^{8}$ We have tried different lags and also alternative simple GARCH tests, with no great differences. Of course there is a large set of alternative GARCH-related measures.
} 
country than others, but finding which is best for each is a task beyond the scope of this paper. However, we note that without knowing the nature of the complex dynamics, it will be very hard for any particular government to intervene with confidence in its financial markets to achieve a given result. Unexpected things may well happen.

\section{Discussion and Conclusions}

We have shown that for a set of 23 markets around the world, there is strong evidence of the presence of nonlinear speculative bubbles in their stock markets during the period of 19932015. Regime switching tests rejected the null hypothesis of no bubbles for all countries. The rescaled range tests also find rejection for the same null hypothesis for all countries. Moreover, the test for nonlinearity beyond ARCH effects using the BDS statistic rejected the null of no such nonlinearity. For most of these tests the rejection of the null was overwhelming.

We recognize that we may not have accurately specified the fundamentals of the stock market. Yet, at a minimum our findings show that the stock markets in just about all of the countries in our sample have exhibited considerable volatility, persistence and non-linearities during the study period; it is in effect what the empirical tests used here can claim to show. Even if the existence of true speculative bubbles is not proved, the markets in these countries have clearly experienced large and sudden fluctuations. Many of these fluctuations are likely to be due to speculative bubbles. This is further supported by the fact that these fluctuations have tended to be far greater than attributable to the underlying fluctuations of macroeconomic variables as shown the macro-economic data provided in tables 1 and 2. Additionally, the reported and anecdotal evidence out of most of these countries suggests that market participants believe that they have frequently observed such bubbles. This long term trend appears to have been somewhat moderated in the post-Global Crisis period, which may have led to attenuation of the speculative proclivities to some extent. Yet, the overall picture is that there seems to be a secular trend towards increasing tendency for the market to exhibit speculative behavior. We have discussed how the period under study has been characterized by the financialization phenomenon. We have not conducted a robust statistical test of the association of the observation of increased incidence of bubbles and the financialization of the economies. Nevertheless, our findings provide a prima facie evidence of the association between the two.

The apparently linkage of the prevalence of bubbles and financialization certainly raises public policy challenges for the governments and the financial regulators. Participants in the financial markets do not like excessive volatility, and certainly market crashes can have 
devastating consequences for the economy. Indeed, macro-economic policies in most countries seek to stabilize financial markets and to deflate asset bubble. However, it may well be that such bubbles are an inevitable part of the development of financial systems particularly in the emerging market economies, but the markets in more developed and established economies are not immune to such bouts either.

The conundrum for policymakers is that while bubbles can distort economic allocation and activity, they may also be an inevitable in process of the development. Theoretical models of smooth growth do not reflect the reality of the development experience. In reality development involves spurts of growth associated with investment surges in particular sectors. Such investment surges may well require outbreaks of excessive enthusiasm, the "animal spirits" of Keynes, in order to bring forth the investment surge. Such outbreaks of enthusiasm will readily show up in stock markets as outbreaks of enthusiasm regarding the stock in such a sector, with the likelihood of speculative bubbles in those stocks emerging. As long as financial markets exist it may be impossible to avoid speculative bubbles. Increasing experimental evidence shows the tendency to bubbles as deeply rooted in the human psyche, occurring even when agents are fully informed about the situations that they are in (Porter and Smith, 1994).

The price of slowing the growth of the financial sector to ward off ill-effects of financialization and possibly avoiding bubbles may be slower economic growth. Certainly it is possible for countries to increase regulation of the financial sector or use either direct capital controls or indirect monetary policy tools such as raising interest rates or margin requirements. However, the demand for modern and innovative financial products from market participants will likely continue to be strong, who may bring political pressure to bear to resist such efforts. Broader contractionary monetary policy can simply slow growth and bring on a recession, and raise unemployment; governments, therefore, face hard choices. Also, the presence of nonlinearities suggests that these bubbles are complex, so that predicting the impacts of trying to manage them through any policies may be difficult, certainly without a better understanding of the particular dynamics of a particular country's financial markets.

The financial crises of 2007 caution us that the financial innovations and availability of low cost financing may also bring risks and dangers, including the risk of spawning of bubbles. However, the experience of this crisis also suggests that these problems are broader and may affect any economy whose financial markets are connected with those of the rest of the world. Again, bubbles and crashes may be inevitable, with the forward march of globalization and the 
expansion of financial instruments in developing financial markets simply making this inevitability all that more unavoidable. It may be that the best that the governments can do is to ensure that the victims of the crashes are assisted in such ways as can be arranged and managed through social safety nets, without harming the broader functioning of their economic systems and development strategies. 


\section{References}

Ahmed, E., Koppl, R., Rosser, J.B., Jr., and White, M.V. 1997. Complex bubble persistence in closed-end country funds. Journal of Economic Behavior and Organization 32, 19-37.

Ahmed, E., Li, H., Rosser, J.B., Jr. Nonlinear bubbles in Chinese stock markets in the 1990s. Eastern Economic Journal 32, 1-18.

Ahmed, E., Rosser, J.B., Jr., and Uppal, J.Y. 1996. Asset speculative bubbles in emerging markets: The case of Pakistan. Pakistan Economic and Social Review 34, 97-118.

Ahmed, E., Rosser, J.B., Jr., and Uppal, J.Y. 2010. Emerging markets and stock market bubbles: Nonlinear speculation? Emerging Markets, Finance, and Trade 46, 73-91.

Aalbers, M. B., 2015. The potential for financialization, Dialogues in Human Geography, 5(2), 214-219.

Aalbers, M. B., van Loon, J., and Fernandez, R., 2015. The financialization of a social housing provider, Paper presented at the RC21 International Conference on "The Ideal City: between myth and reality. Representations, policies, contradictions and challenges for tomorrow's urban life" Urbino. http://www.rc21.org/en/conferences/urbino2015/

Aalbers, M. B. 2008. The Financialization of Home and the Mortgage Market Crisis. Competition \& Change, 12(2), 148-166.

Baumol. W.J. 1957. Speculation, profitability, and instability. Review of Economics and Statistics 34, 263-271.

J. Bhagwati. 2007. In Defense of Globalizaton, with a New Afterword. New York: Oxford University Press.

Bischi, G.-I., Gallegati, M., Gardini, L., Leombrini, R., and Palestrini, A. 2006. Herd behavior and non-fundamental asset price fluctuations in financial markets. Macroeconomic Dynamics 10, 502-528.

Black, F. 1986. Noise. Journal of Finance 41, 529-542.

Blanchard, O. and Watson, M.W. 1982. Bubbles, rational expectations, and financial markets. In P. Wachtel, ed., Crises in the Economic and Financial Structure. Lexington: Lexington Books,295-315.

Brock, W.A., Dechert,W.D., Scheinkman, J.A., and LeBaron, B. A test for independence based on the correlation dimension. Econometric Reviews 15, 197-235.

Brock, W.A. and Hommes, C. 1997. A rational route to randomness. Econometrica 65, 10591095.

Canova, F. and Ito, T. 1991. The time series properties in the risk premium of the yen/dollar exchange rate. Journal of Applied Econometrics 22, 213-223.

Chiarella, C., Gallegati, M., Leombrini, R., and Palestrini, A. 2003. Asset price dynamics using heterogeneous interacting agents. Computational Economics 22, 213-223.

Cloke, J. 2010. Capital is dead: Long live ultra-capital. In T. Lagoarde-Segot (Ed.), After the crisis: Rethinking finance. Nova Science, 1-16.

Cloke, J. 2013. Actor-network capitalism and the evolution of ultra-capital. Working paper, University of Helsinki.

Ciner, C. and Karagozlu, A.K. 2008. Information asymmetries, speculation and foreign trading activity: Evidence from an emerging market. International Review of Financial Analysis 17, 664-680.

Day, R.H. and Huang, W. 1990. Bulls, bears, and market sheep. Journal of Economic Behavior and Organization 14, 299-329.

DeLong, J.B., Shleifer, A., Summers, L.H., and Waldmann, R. 1991. The survival of noise traders in financial markets. Journal of Business 64, 1-19.

Engel, R. and Hamilton,J.D. 1990. Long swings in the dollar: Are they in the data and do markets know it? American Economic Review 80, 689-713. 
Engle, R.F. 1982. Autoregressive conditional heteroscedasticity with estimation of the variance of United Kingdom inflation. Econometrica 50, 251-276.

Feller, W. 1951. The asymptotic distribution of the range of sums of independent random variables. Annals of Mathematical Statistics 22, 427-432.

Flood,R.P. and Garber, P.M. 1980. Market fundamentals versus price level bubbles: The first tests. Journal of Political Economy 88, 745-776.

Föllmer, H., Horst, U., and Kirman, A. 2005. Equilibria in financial markets with heterogeneous agents: A probabilistic approach. Journal of Mathematical Economics 41, 123-155.

Gallegati, M., Palestrini, A., Rosser, J.B., Jr. 2011. The period of financial distress in speculative markets: Interacting heterogeneous agents and financial constraints. Macroeconomic Dynamics 15, 60-79.

Hamilton, J.D. 1989. A new approach to the economic analysis of nonstationary time series and the business cycle. Econometrica 57, 357-384.

Hamilton, J.D. 1994. Time-Series Analysis. Princeton: Princeton University Press.

Hiremath, G.S. 2014. Indian Stock Market: An Empirical Analysis of Informational Efficiency. New Delhi, Springer.

Hurst, H.E. 1951. Long term storage capacity of reservoirs. Transactions of the American Society of Civil Engineers 116, 770-799.

Jiang, Z.-Q., Zhou, W.-X., Sornette, D., Woodard, R., Bastiaensean, and Cauwels, P. 2010. Bubble diagnosis and prediction of the 2005-2007 and 2008-2009 Chinese stock market bubbles. Journal of Economic Behavior and Organization 74, 149-161.

Kaminsky, G.L. and Reinhart, C.M. 1999. The twin crises: the causes of banking and balance-ofpayment problems, American Economic Review, 89(3), 473-500.

Kindleberger, C.P. 2000. Manias, Panics, and Crashes, $4^{\text {th }}$ edition. New York: Wiley.

Minsky, H.P. 1972. Financial instability revisited: The economics of disaster. Reappraisal of the Federal Reserve Discount Mechanism 3, 97-136.

Lo, A.W. 1991. Long memory in stock prices. Econometrica 59, 1279-1313.

Mandelbrot, B.B. 1972. Statistical methodology for nonperiodic cycles: From covariance to R/S analysis. Annals of Economic and Social Measurement 1, 259-290.

Palley, T. I. 2007. Financialization: What it is and why it matters, Paper presented at a conference on "Finance-led Capitalism? Macroeconomic Effects of Changes in the Financial Sector, " the Hans Boeckler Foundation, Berlin, Germany.

Rosser, J.B., Jr., Rosser, M.V., and Gallegati, M. 2012. A Minsky-Kindleberger perspective on the financial crisis. Journal of Economic Issues 45, 449-458.

Sarkar, N. and Mukhopadhyay. 2005. Testing predictability and nonlinear dependence in the Indian stock market. Emerging Markets, Finance and Trade 41, 7-44.

Shiller, R.J. 2015. Irrational Exuberance, $3^{\text {rd }}$ edition. Princeton: Princeton University Press.

Thiele, T.A. 2014. Multiscaling and stock market efficiency in China. Review of Pacific Basin Financial Markets and Policies 17, doi 1450023.

Tirole, J. 1985. Asset bubbles and overlapping generations. Econometrica 53, 1499-1528.

Vitali, S., Glattfelder, J. B., and Battiston, S. 2011. The network of global corporate control. PLoS One. 2011; 6(10): e25995. Published online 2011 Oct 26. doi: 10.1371/journal.pone.0025995

Walter, C., 2016. The financial Logos: The framing of financial decision-making by mathematical modelling, Research in International Business and Finance, 37, 597-604.

Zeeman, E.C. 1974. On the unstable behavior of the stock exchange. Journal of Mathematical Economcs 1, 39-44. 
Table 1-a: Salient Statistics of the Economies and Equity Markets

\begin{tabular}{|c|c|c|c|c|c|c|c|c|c|c|c|c|c|c|c|c|c|c|c|c|c|}
\hline \multirow[b]{3}{*}{ Country } & \multicolumn{7}{|c|}{ GDP at market prices (current US\$ billions) } & \multicolumn{7}{|c|}{ GDP per capita (current US\$) } & \multicolumn{7}{|c|}{$\begin{array}{l}\text { Market capitalization of listed domestic companies } \\
\text { (current US\$) }\end{array}$} \\
\hline & \multirow[b]{2}{*}{1992} & \multirow[b]{2}{*}{2001} & \multirow[b]{2}{*}{2008} & \multirow[b]{2}{*}{2013} & \multicolumn{3}{|c|}{ Annual growth rates } & \multirow[b]{2}{*}{1992} & \multirow[b]{2}{*}{2001} & \multirow[b]{2}{*}{2008} & \multirow[b]{2}{*}{2013} & \multicolumn{3}{|c|}{ Annual growth rates } & \multirow[b]{2}{*}{1992} & \multirow[b]{2}{*}{2001} & \multirow[b]{2}{*}{2008} & \multirow[b]{2}{*}{2013} & \multicolumn{3}{|c|}{ Annual growth rates } \\
\hline & & & & & $\begin{array}{c}1992- \\
01\end{array}$ & $\begin{array}{c}2002- \\
08\end{array}$ & $\begin{array}{c}2009- \\
13\end{array}$ & & & & & $\begin{array}{c}1992- \\
01\end{array}$ & $\begin{array}{c}2002- \\
08\end{array}$ & $\begin{array}{c}2009- \\
13\end{array}$ & & & & & \begin{tabular}{|c|}
$1992-$ \\
01
\end{tabular} & \begin{tabular}{|c|}
$2002-$ \\
08
\end{tabular} & \begin{tabular}{|c|}
$2009-$ \\
13
\end{tabular} \\
\hline Brazil & 401 & 560 & 1,695 & 2,392 & $3.8 \%$ & $17.1 \%$ & $7.1 \%$ & 2,578 & 3,136 & 8,700 & 11,711 & $2.2 \%$ & $15.7 \%$ & $6.1 \%$ & .. & 186 & 592 & 1,020 & .. & $18.0 \%$ & $11.5 \%$ \\
\hline Chile & 44 & 72 & 180 & 277 & $5.6 \%$ & $13.9 \%$ & $9.0 \%$ & 3,278 & 4,710 & 10,791 & 15,742 & $4.1 \%$ & $12.6 \%$ & $7.8 \%$ & 32 & 56 & 132 & 265 & $6.4 \%$ & $12.9 \%$ & $15.0 \%$ \\
\hline Colombia & 49 & 98 & 244 & 380 & $8.0 \%$ & $13.9 \%$ & $9.3 \%$ & 1,386 & 2,396 & 5,434 & 8,028 & $6.3 \%$ & $12.4 \%$ & $8.1 \%$ & .. & .. & 88 & 203 & .. & 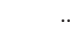 & $18.2 \%$ \\
\hline Czech Rep & 34 & 67 & 235 & 208 & $7.7 \%$ & $19.6 \%$ & $-2.4 \%$ & 3,339 & 6,595 & 22,649 & 19,814 & $7.9 \%$ & $19.3 \%$ & $-2.6 \%$ & .. & 8 & 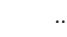 & .. & .. & .. & \\
\hline Hong Kong & 104 & 169 & 219 & 276 & $5.5 \%$ & $3.8 \%$ & $4.7 \%$ & 17,976 & 25,230 & 31,516 & 38,364 & $3.8 \%$ & $3.2 \%$ & $4.0 \%$ & 172 & 506 & 1,329 & 3,101 & $12.7 \%$ & $14.8 \%$ & $18.5 \%$ \\
\hline Hungary & 39 & 54 & 157 & 134 & $3.7 \%$ & $16.6 \%$ & $-3.1 \%$ & 3,717 & 5,267 & 15,650 & 13,585 & $3.9 \%$ & $16.8 \%$ & $-2.8 \%$ & .. & .. & 18 & 20 & .. & .. & 1.4 \\
\hline India & 293 & 494 & 1,224 & 1,862 & $6.0 \%$ & $13.8 \%$ & $8.7 \%$ & 324 & 461 & 1,023 & 1,455 & $4.0 \%$ & $12.1 \%$ & $7.3 \%$ & .. & .. & 647 & 1,139 & .. & . & $12.0 \%$ \\
\hline Indonesia & 139 & 160 & 510 & 910 & $1.6 \%$ & $18.0 \%$ & $12.3 \%$ & 741 & 748 & 2,168 & 3,624 & $0.1 \%$ & $16.4 \%$ & $10.8 \%$ & .. & 27 & 99 & 347 & 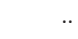 & $20.3 \%$ & $28.5 \%$ \\
\hline Israel & 66 & 131 & 217 & 292 & $7.9 \%$ & $7.5 \%$ & $6.2 \%$ & 12,838 & 20,306 & 29,657 & 36,281 & $5.2 \%$ & $5.6 \%$ & $4.1 \%$ & 30 & 58 & 108 & 203 & $7.6 \%$ & $9.3 \%$ & $13.5 \%$ \\
\hline Korea, Rep. & 356 & 533 & 1,002 & 1,306 & $4.6 \%$ & $9.4 \%$ & $5.4 \%$ & 8,140 & 11,256 & 20,475 & 25,998 & $3.7 \%$ & $8.9 \%$ & $4.9 \%$ & 108 & 194 & 471 & 1,235 & $6.8 \%$ & $13.5 \%$ & 21.3 \\
\hline Malaysia & 59 & 93 & 231 & 323 & $5.1 \%$ & $13.9 \%$ & $7.0 \%$ & 3,081 & 3,879 & 8,487 & 10,974 & $2.6 \%$ & $11.8 \%$ & $5.3 \%$ & 89 & 119 & 189 & 500 & $3.3 \%$ & $6.9 \%$ & $21.5 \%$ \\
\hline Mexico & 364 & 725 & 1,101 & 1,259 & $8.0 \%$ & $6.2 \%$ & $2.7 \%$ & 4,080 & 6,952 & 9,579 & 10,173 & $6.1 \%$ & $4.7 \%$ & $1.2 \%$ & 139 & 126 & 234 & 526 & $-1.0 \%$ & $9.2 \%$ & $17.6 \%$ \\
\hline Morocco & 32 & 38 & 93 & 107 & $1.8 \%$ & $13.7 \%$ & $3.0 \%$ & 1,228 & 1,275 & 2,906 & 3,156 & $0.4 \%$ & $12.5 \%$ & $1.7 \%$ & .. & .. & & 54 & .. & .. & \\
\hline Pakistan & 49 & 72 & 170 & 231 & $4.5 \%$ & $13.0 \%$ & $6.3 \%$ & 428 & 512 & 1,043 & 1,275 & $2.0 \%$ & $10.7 \%$ & $4.1 \%$ & .. & 5 & 23 & .. & .. & $25.0 \%$ & \\
\hline Peru & 35 & 52 & 122 & 202 & $4.3 \%$ & $13.0 \%$ & $10.7 \%$ & 1,547 & 1,965 & 4,245 & 6,604 & $2.7 \%$ & $11.6 \%$ & $9.2 \%$ & .. & 10 & 38 & 81 & & $21.3 \%$ & $16.4 \%$ \\
\hline Philippines & 53 & 76 & 174 & 272 & $4.1 \%$ & $12.5 \%$ & $9.3 \%$ & 814 & 958 & 1,929 & 2,787 & $1.8 \%$ & $10.5 \%$ & $7.6 \%$ & .. & 21 & 52 & 217 & & $13.7 \%$ & $33.1 \%$ \\
\hline Poland & 93 & 191 & 530 & 524 & $8.4 \%$ & $15.7 \%$ & $-0.2 \%$ & 2,412 & 4,981 & 13,906 & 13,776 & $8.4 \%$ & $15.8 \%$ & $-0.2 \%$ & .. & 26 & 91 & 205 & & $19.6 \%$ & $17.6 \%$ \\
\hline Russian Fed & 460 & 307 & 1,661 & 2,079 & $-4.4 \%$ & $27.3 \%$ & $4.6 \%$ & 3,096 & 2,100 & 11,635 & 14,487 & $-4.2 \%$ & $27.7 \%$ & $4.5 \%$ & .. & .. & * & 771 & .. & .. & \\
\hline Thailand & 111 & 120 & 291 & 420 & $0.9 \%$ & $13.5 \%$ & $7.6 \%$ & 1,930 & 1,897 & 4,385 & 6,229 & $-0.2 \%$ & $12.7 \%$ & $7.3 \%$ & 57 & 36 & 103 & 354 & $-5.0 \%$ & $16.3 \%$ & $28.0 \%$ \\
\hline Singapore & 52 & 89 & 192 & 302 & $6.2 \%$ & $11.6 \%$ & $9.5 \%$ & 16,144 & 21,577 & 39,721 & 55,980 & $3.3 \%$ & $9.1 \%$ & $7.1 \%$ & 49 & 116 & 265 & 744 & $10.0 \%$ & $12.6 \%$ & $22.9 \%$ \\
\hline South Africa & 131 & 122 & 287 & 366 & $-0.8 \%$ & $13.1 \%$ & $5.0 \%$ & 3,557 & 2,706 & 5,812 & 6,890 & $-3.0 \%$ & $11.5 \%$ & $3.5 \%$ & 164 & 147 & 483 & 943 & $-1.2 \%$ & $18.5 \%$ & $14.3 \%$ \\
\hline Sri Lanka & 10 & 16 & 41 & 74 & $5.5 \%$ & $14.5 \%$ & $12.8 \%$ & 557 & 838 & 2,011 & 3,628 & $4.6 \%$ & $13.3 \%$ & $12.5 \%$ & .. & 1 & 4 & 19 & .. & $18.2 \%$ & $34.4 \%$ \\
\hline Total & 2,974 & 4,238 & 10,576 & 14,198 & & & & & & & & & & & 840 & 1,644 & 4,966 & 11,946 & & & \\
\hline Average & 135 & 193 & 481 & 645 & $4.5 \%$ & $13.7 \%$ & $6.2 \%$ & 4,236 & 5,898 & 11,533 & 14,116 & $3.0 \%$ & $12.5 \%$ & $5.1 \%$ & 93 & 97 & 261 & 597 & $4.4 \%$ & $15.6 \%$ & 19.2 \\
\hline
\end{tabular}


Table1-b:SalientStatisticsoftheEconomiesandEquityMarkets

\begin{tabular}{|c|c|c|c|c|c|c|c|c|c|c|c|c|c|c|c|c|c|c|c|c|}
\hline \multirow[b]{2}{*}{ Country } & \multicolumn{4}{|c|}{$\begin{array}{l}\text { Stocks traded, total value } \\
\text { (current US\$) }\end{array}$} & \multicolumn{4}{|c|}{$\begin{array}{l}\text { Listed domestic } \\
\text { companies, total }\end{array}$} & \multicolumn{4}{|c|}{$\begin{array}{l}\text { Market capitalization of listed } \\
\text { domestic companies (\% of GDP) }\end{array}$} & \multicolumn{4}{|c|}{$\begin{array}{l}\text { Stocks traded, total value (\% } \\
\text { of GDP) }\end{array}$} & \multicolumn{4}{|c|}{$\begin{array}{l}\text { Stocks traded, turnover ratio of } \\
\text { domestic shares (\%) }\end{array}$} \\
\hline & 1992 & 2001 & 2008 & 2013 & 1992 & 2001 & 2008 & 2013 & 1992 & 2001 & 2008 & 2013 & 1992 & 2001 & 2008 & 2013 & 1992 & 2001 & 2008 & 2013 \\
\hline Brazil & .. & 65 & 572 & 744 & 565 & 426 & 383 & 352 & .. & 33.3 & 34.9 & 42.7 & .. & 11.6 & 33.8 & 31.1 & .. & 31.5 & 58.3 & 66.2 \\
\hline Chile & 2 & 4 & 29 & 41 & 244 & 249 & 235 & 227 & 72.5 & 77.8 & 73.4 & 95.8 & 4.3 & 5.6 & 16.1 & 14.9 & 6.4 & 7.0 & 16.8 & 14.3 \\
\hline Colombia & .. & .. & 18 & 25 & .. & .. & 89 & 72 & .. & .. & 36.0 & 53.3 & .. & .. & 7.4 & 6.6 & .. & .. & 19.0 & 10.9 \\
\hline Czech Republic & .. & .. & .. &.. & .. & 47 & .. & .. & .. & 12.1 & .. & $\cdot$ & .. & .. & .. &.. & .. & .. & .. & .. \\
\hline Hong Kong & 79 & 238 & 1,569 & 1,324 & 386 & 857 & 1,251 & 1,553 & 164.9 & 298.7 & 606.0 & 1124.5 & 75.3 & 140.7 & 715.6 & 480.1 & 53.5 & 42.2 & 78.8 & 44.6 \\
\hline Hungary & .. & .. & 28 & 11 & .. & 0 & 40 & 50 & .. & .. & 11.8 & 14.7 & .. & .. & 17.6 & 8.1 & .. & .. & 85.3 & 53.4 \\
\hline India & .. & .. & 925 & 534 & .. & 5795 & 4,921 & 5,294 & .. & .. & 52.9 & 61.2 & .. & .. & 75.6 & 28.7 & .. & .. & 75.0 & 44.4 \\
\hline Indonesia & .. & 9 & 76 & 99 & .. & 315 & 396 & 483 & .. & 16.9 & 19.4 & 38.1 & .. & 5.8 & 14.9 & 10.9 & .. & 24.3 & 48.9 & 25.5 \\
\hline Israel & 13 & 15 & 96 & 56 & 377 & .. & 630 & 491 & 45.2 & 44.1 & 49.7 & 69.5 & 19.9 & 11.5 & 44.3 & 19.0 & 59.5 & 24.1 & 56.0 & 30.4 \\
\hline Korea, Rep. & 115 & 374 & 1,188 & 1,334 & 688 & 688 & 1,789 & 1,798 & 30.2 & 36.5 & 47.0 & 94.6 & 32.3 & 70.2 & 118.5 & 102.2 & 112.8 & 218.2 & 149.1 & 110.5 \\
\hline Malaysia & 19 & 21 & 83 & 143 & 363 & 804 & 972 & 900 & 150.4 & 128.2 & 82.0 & 154.8 & 32.3 & 23.0 & 36.1 & 44.2 & 26.3 & 18.4 & 32.4 & 29.6 \\
\hline Mexico & 44 & 60 & 90 & 174 & 199 & 167 & 125 & 138 & 38.2 & 17.4 & 21.3 & 41.8 & 12.1 & 8.3 & 8.2 & 13.8 & 36.6 & 48.0 & 28.5 & 33.1 \\
\hline Morocco & .. & .. & .. & 3 & .. & 55 & 77 & 75 & .. & .. & .. & 50.2 & .. & .. & .. & 3.0 & .. & .. & .. & 6.1 \\
\hline Pakistan & .. & .. & .. &.. & .. & .. & 629 & 550 & .. & 6.8 & 13.7 & & .. & .. & .. & .. & .. & .. & .. & .. \\
\hline Peru & .. & 1 & 5 & 4 & .. & 204 & 201 & 212 & .. & 19.0 & 31.2 & 40.1 & .. & 1.8 & 3.9 & 1.9 & .. & 9.7 & 8.8 & 4.3 \\
\hline Philippines & .. & 3 & 12 & 45 & .. & 230 & 244 & 254 & .. & 27.9 & 29.9 & 79.9 & .. & 4.1 & 7.1 & 16.4 & .. & 13.1 & 16.0 & 20.0 \\
\hline Poland & .. & 10 & 54 & 73 & .. & 230 & 432 & 869 & .. & 13.7 & 17.1 & 39.0 & .. & 5.3 & 10.1 & 14.0 & .. & 35.5 & 35.5 & 38.5 \\
\hline Russian Fed & .. & .. & .. & 236 & .. &.. & 329 & 261 & .. & .. & .. & 37.1 & .. &.. & .. & 11.3 & .. & .. & .. & 29.5 \\
\hline Thailand & 71 & 31 & 106 & 350 & 315 & 382 & 525 & 584 & 51.4 & 29.9 & 35.4 & 84.3 & 64.1 & 25.8 & 36.4 & 83.3 & 149.9 & 95.3 & 70.6 & 94.0 \\
\hline Singapore & .. & 71 & 253 & 279 & 181 & 318 & 455 & 479 & 93.8 & 129.6 & 137.8 & 246.3 & .. & 79.6 & 131.6 & 92.2 & .. & 53.0 & 62.9 & 36.9 \\
\hline South Africa & 8 & 50 & 284 & 318 & 642 & 510 & 367 & 322 & 125.7 & 121.4 & 168.3 & 257.4 & 6.1 & 41.5 & 99.0 & 86.9 & 4.6 & 28.7 & 43.3 & 34.4 \\
\hline Sri Lanka & .. & 0 & 1 & 2 &.. & 238 & 235 & 289 & .. & 8.5 & 10.5 & 25.3 & .. & 1.0 & 2.4 & 2.1 & .. & 12.5 & 16.4 & 8.6 \\
\hline Total & 351 & 954 & 5,389 & 5,794 & 3,960 & 1,515 & 14,325 & 15,253 & & & & & & & & & & & & \\
\hline Average & 44 & 64 & 299 & 290 & 396 & 640 & 682 & 726 & 86 & 60 & 78 & 133 & 31 & 29 & 77 & 54 & 56 & 44 & 50 & 37 \\
\hline
\end{tabular}


Table2-a:Wald Test for Bubbles

Sampleperiod:1/1/93to3/5/15

\begin{tabular}{lr} 
Country & H0:P=1-P2; Waldtest $\left(\chi^{2}\right)$ \\
\hline Brazil & 39191.49 \\
Chile & 643.90 \\
Colombia & 1294.71 \\
Czech Republic & 6016.80 \\
Hong Kong & 15177.18 \\
Hungary & 5369.79 \\
India & 8387.21 \\
Indonesia & 3443.69 \\
Israel & 5991.35 \\
Korea & 52099.97 \\
Malaysia & 4737.63 \\
Mexico & 13562.08 \\
Morocco & 414.77 \\
Pakistan & 3808.57 \\
Peru & 1902.77 \\
Philippines & 2807.17 \\
Poland & 6983.03 \\
Russia & 6830.12 \\
Singapore & 10483.43 \\
South Africa & 6796.83 \\
Sri Lanka & 1430.53 \\
Taiwan & 10682.25 \\
Thailand & 3371.86 \\
\hline
\end{tabular}

Critical Value $\chi 2=3.84$

Steps involved in Wald test: (i) Each variable series was transformed into logarithmic first differences and used in VAR procedure (with 8 lags).(ii) Stock returns are endogenous variable while other variables are short-term interest rates, exchange rate and world stock returns. (iii) VAR residuals related to each country's stock return variable were then used to run the Wald tests. 
Table 2-b: Wald Test for Bubbles: Sub-samples

\begin{tabular}{|l|r|r|r|r|r|}
\hline Country & Subsample 1 & Subsample 2 & Subsample 3 & Subsample 4 \\
\hline Brazil & 25.56 & 545.94 & $1,212.17$ & 0.10 \\
\hline Chile & $5,001.99$ & 209.57 & $2,994.26$ & 0.83 \\
\hline Columbia & 7.62 & 112.82 & 631.29 & NA \\
\hline Zzech & 25.56 & 545.94 & $1,212.17$ & 0.10 \\
\hline Hongkong & 313.02 & 195.81 & 761.01 & 1.51 \\
\hline India & 0.16 & NA & & $5,473.77$ & $2,012.89$ \\
\hline Indonesia & 20.44 & 873.49 & $4,345.50$ & $13,695.03$ \\
\hline Israel & 2.48 & 446.36 & 236.34 & $1,627.35$ \\
\hline Korea & 16.37 & 4.04 & $1,914.01$ & $1,332.74$ \\
\hline Malaysia & 770.59 & 67.59 & 144.72 & 642.11 \\
\hline Mexico & 162.05 & $1,838.56$ & $5,119.09$ & 16.78 \\
\hline Morocco & 21.73 & 12.84 & 4.68 & \\
\hline Pakistan & $1,016.45$ & $2,680.92$ & NA & & \\
\hline Peru & 278.27 & 13.15 & 635.65 & 172.78 \\
\hline Phillippines & $1,842.54$ & 146.67 & 7.12 & 686.14 \\
\hline Poland & 967.10 & 643.06 & $5,895.50$ & $20,486.06$ \\
\hline Russia & $1,198.12$ & $2,442.11$ & $1,614.21$ & 521.50 \\
\hline Singapore & 69.41 & 4.49 & $2,787.18$ & $2,672.37$ \\
\hline South Africa & 123.68 & 569.32 & $2,129.70$ & $11,724.56$ \\
\hline Srilanka & 90.98 & 110.48 & 626.73 & 168.11 \\
\hline Taiwan & 352.92 & 25.64 & 456.60 & $35,813.51$ \\
\hline Thailand & 101.34 & 87.83 & NA & 115.48 \\
\hline
\end{tabular}

\section{CriticalValuex $2=3.84$}

Steps involved in Wald test: (i) Each variable series was transformed into logarithmic first differences and used in VAR procedure (with 8 lags). (ii) Stock returns are endogenous variable while other variables are short-term interest rates, exchange rates and world stock returns. (iii) VAR residuals related to each country's stock return variable were then used to run the Wald tests.

Full sample, $1 / 1 / 1993$ to $3 / 5 / 15$ was divided into four sub-samples. This division also roughly corresponded to the statistics on the economies and the markets provided in tables 1 and 2 .

Sub-sample 1: Jan1993-Dec1996 - 4 years, pre-dotcom bubble period, market liberalization period

Sub-sample 2: Jan1997-Dec2001 - 5 years, dotcom bubble and bust Sub-sample 3: Jan2002-Dec2007 - 6 years, real estate bubble and bust Sub-sample 4: Jan 2008-Mar2015 - 6+ years, great recession and recovery. NA refers to handful of sub-samples where sufficient data were not available. 
Table3: Estimated Hurst Coefficient and Associated F statistics For Chow Test

\begin{tabular}{|c|c|c|c|c|c|c|c|}
\hline \multirow{2}{*}{\multicolumn{2}{|c|}{ Country }} & \multicolumn{3}{|c|}{ Pre2008 } & \multicolumn{3}{|c|}{ Post2008 } \\
\hline & & $\begin{array}{l}\text { Sample } \\
\text { Size }\end{array}$ & $\begin{array}{c}\text { Hurst } \\
\text { Coefficient }\end{array}$ & $\begin{array}{c}\text { Computed } \\
\text { F }\end{array}$ & $\begin{array}{l}\text { Sample } \\
\text { Size }\end{array}$ & $\begin{array}{c}\text { Hurst } \\
\text { Coefficient }\end{array}$ & $\begin{array}{c}\text { Computed } \\
\text { F }\end{array}$ \\
\hline 1 & Brazil & 289 & 0.43 & 397 & 279 & 0.62 & 58,578 \\
\hline 2 & Chile & 488 & 0.60 & 133,992 & 27 & 0.68 & 1,304 \\
\hline 3 & Colombia & 462 & 0.57 & 37,660 & 249 & 0.57 & 53,001 \\
\hline 4 & Czech Republic & 456 & 0.61 & 29,376 & 249 & 0.55 & 31,957 \\
\hline 5 & Hong Kong & 488 & 0.58 & 95,503 & 248 & 0.56 & 33,878 \\
\hline 6 & Hungary & 420 & 0.58 & 32,639 & 249 & 0.53 & 30,926 \\
\hline 7 & India & 431 & 0.62 & 102,332 & 249 & 0.54 & 28,509 \\
\hline 8 & Indonesia & 487 & 0.61 & 127,116 & 249 & 0.54 & 37,998 \\
\hline 9 & Israel & 440 & 0.58 & 44,384 & 249 & 0.53 & 26,531 \\
\hline 10 & South Korea & 462 & 0.58 & 83,144 & 249 & 0.51 & 21,606 \\
\hline 11 & Malaysia & 488 & 0.60 & 71,016 & 216 & 0.54 & 15,108 \\
\hline 12 & Mexico & 409 & 0.57 & 40,860 & 249 & 0.58 & 39,673 \\
\hline 13 & Morocco & 750 & 0.62 & 71 & 249 & 0.58 & 71,151 \\
\hline 14 & Pakistan & 1624 & 0.59 & 51 & 249 & 0.54 & 38,034 \\
\hline 15 & Peru & 431 & 0.60 & 43,587 & 260 & 0.58 & 38,992 \\
\hline 16 & Philippines & 487 & 0.57 & 117,544 & 249 & 0.54 & 34,069 \\
\hline 17 & Poland & 477 & 0.56 & 65,302 & 249 & 0.50 & 20,203 \\
\hline 18 & Russia & 446 & 0.59 & 56,074 & 249 & 0.54 & 39,002 \\
\hline 19 & Singapore & 462 & 0.60 & 148,291 & 249 & 0.56 & 25,074 \\
\hline 20 & South Africa & 655 & 0.54 & 96,591 & 249 & 0.46 & 16,608 \\
\hline 21 & Sri Lanka & 462 & 0.62 & 139,346 & 249 & 0.56 & 24,380 \\
\hline 22 & Taiwan & 487 & 0.58 & 92,618 & 246 & 0.51 & 37,429 \\
\hline 23 & Thailand & 487 & 0.58 & 132,148 & 249 & 0.51 & 26,497 \\
\hline
\end{tabular}


Table4:BDSTestResults

\begin{tabular}{|c|c|c|c|c|c|c|c|c|c|c|}
\hline \multirow[b]{2}{*}{ Country } & \multirow[b]{2}{*}{ NOB } & \multicolumn{3}{|c|}{ Dimension2 } & \multicolumn{3}{|c|}{ Dimension3 } & \multicolumn{3}{|c|}{ Dimension4 } \\
\hline & & BDS Stat & z-Stat & Prob. & BDS Stat & z-Stat & Prob. & BDS Stat & z-Stat & Prob. \\
\hline Brazil & 5787 & 0.0207 & 12.72 & 0.0000 & 0.0485 & 18.68 & 0.0000 & 0.0738 & 23.86 & 0.0000 \\
\hline Chile & 5787 & 0.0192 & 13.53 & 0.0000 & 0.0414 & 18.41 & 0.0000 & 0.0568 & 21.22 & 0.0000 \\
\hline Colombia & 5786 & 0.0271 & 19.87 & 0.0000 & 0.0525 & 24.23 & 0.0000 & 0.0685 & 26.59 & 0.0000 \\
\hline Czech Rep. & 5786 & 0.0224 & 18.03 & 0.0000 & 0.0471 & 23.87 & 0.0000 & 0.0645 & 27.47 & 0.0000 \\
\hline Hong Kong & 5786 & 0.0205 & 16.43 & 0.0000 & 0.0408 & 20.63 & 0.0000 & 0.0567 & 24.14 & 0.0000 \\
\hline Hungary & 5786 & 0.0206 & 16.50 & 0.0000 & 0.0394 & 19.87 & 0.0000 & 0.0529 & 22.38 & 0.0000 \\
\hline India & 5786 & 0.0229 & 18.13 & 0.0000 & 0.0441 & 22.05 & 0.0000 & 0.0595 & 25.07 & 0.0000 \\
\hline Indonesia & 5786 & 0.0315 & 23.81 & 0.0000 & 0.0591 & 28.11 & 0.0000 & 0.0776 & 31.05 & 0.0000 \\
\hline Israel & 5786 & 0.0169 & 13.84 & 0.0000 & 0.0335 & 17.33 & 0.0000 & 0.0461 & 20.06 & 0.0000 \\
\hline South Korea & 5786 & 0.0229 & 17.64 & 0.0000 & 0.0509 & 24.68 & 0.0000 & 0.0729 & 29.67 & 0.0000 \\
\hline Malaysia & 5786 & 0.0384 & 26.57 & 0.0000 & 0.0750 & 32.62 & 0.0000 & 0.1005 & 36.69 & 0.0000 \\
\hline Mexico & 5785 & 0.0168 & 12.69 & 0.0000 & 0.0364 & 17.31 & 0.0000 & 0.0534 & 21.37 & 0.0000 \\
\hline Morocco & 5786 & 0.0238 & 13.61 & 0.0000 & 0.0459 & 16.50 & 0.0000 & 0.0602 & 18.16 & 0.0000 \\
\hline Pakistan & 5794 & 0.0371 & 20.14 & 0.0000 & 0.0696 & 23.72 & 0.0000 & 0.0915 & 26.11 & 0.0000 \\
\hline Peru & 5786 & 0.0310 & 22.47 & 0.0000 & 0.0606 & 27.58 & 0.0000 & 0.0813 & 31.04 & 0.0000 \\
\hline Philippines & 5786 & 0.0183 & 15.92 & 0.0000 & 0.0354 & 19.42 & 0.0000 & 0.0480 & 22.20 & 0.0000 \\
\hline Poland & 5786 & 0.0177 & 14.00 & 0.0000 & 0.0368 & 18.36 & 0.0000 & 0.0518 & 21.75 & 0.0000 \\
\hline Russia & 5786 & 0.0364 & 25.30 & 0.0000 & 0.0723 & 31.66 & 0.0000 & 0.0983 & 36.16 & 0.0000 \\
\hline Singapore & 5786 & 0.0242 & 19.01 & 0.0000 & 0.0499 & 24.73 & 0.0000 & 0.0696 & 29.04 & 0.0000 \\
\hline South Africa & 5786 & 0.0157 & 11.45 & 0.0000 & 0.0325 & 14.92 & 0.0000 & 0.0447 & 17.28 & 0.0000 \\
\hline Sri Lanka & 5786 & 0.0324 & 22.05 & 0.0000 & 0.0634 & 27.05 & 0.0000 & 0.0843 & 30.14 & 0.0000 \\
\hline Taiwan & 5786 & 0.0131 & 10.57 & 0.0000 & 0.0319 & 16.26 & 0.0000 & 0.0470 & 20.13 & 0.0000 \\
\hline Thailand & 5786 & 0.0231 & 18.98 & 0.0000 & 0.0453 & 23.44 & 0.0000 & 0.0609 & 26.44 & 0.0000 \\
\hline
\end{tabular}

